\title{
A LA ESCUCHA DE JEAN-LUC NANCY
}

\author{
Juan Luis Calero Santana \\ UNED \\ jlcaleros@gmail.com
}

\section{Resumen}

Este trabajo se centra en algunos aspectos de la filosofía de Jean-Luc Nancy. Nuestro autor hace tambalear los cimientos de pensamientos asentados por la inercia de la tradición, se despoja de las vestiduras y va por libre de otras voces y libre de sí mismo. Su pensamiento descarna los sellos que han dejado marcas y relieves en la cultura de Occidente, para así ser solo pensamiento que penetra en lo aprendido. Se posiciona fuera del ensimismamiento del pensar condicionado, para inaugurar nuevas formas de afrontar el momento actual de la filosofía.

Palabras clave: sueño, escucha, cuerpo, cristianismo.

\section{LISTENING TO JEAN-LUC NANCY}

\section{Abstract}

This work focuses on some aspects of Jean-Luc Nancy's philosophy. Our author shakes the foundations of thoughts which have been settled by the inertia of tradition, he takes away his vestments and goes freely from other voices and from himself. His thought removes the flesh from the seals that have left marks and prominences in Western culture, to become just a thought which penetrates what has been learnt. He stands out of the absorption of conditioned thought and opens new ways of achieving current philosophy.

KeYwords: dream, listening, body, Christianity. 


\section{INTRODUCCIÓN}

El pensamiento de Jean-Luc Nancy (Bordeaux, 1940) se florea y despliega por diferentes ámbitos. La estética, la política, su ontología referida al cuerpo como atalaya para pensar, el sueño y su oído filosófico ocupan gran parte de las páginas de sus trabajos. En esta aproximación a algunas de las escuchas que Nancy realiza a lo largo de su obra hay que dejar en la percha las etiquetas que han encorsetado, y no han hecho justicia, a nuestro autor al situarlo dentro de una corriente derridiana sin salida, porque a medida que se avanza, se profundiza y reflexiona sobre los trabajos del autor de Corpus más claro se nos hace el panorama tan singular que representa. Nancy se esmera en escuchar desde el perímetro de las cosas, desde los contornos que amenazan con el abismo de lo no pensado.

Su filosofía está puesta en el hoy de tal manera que por ello puede darnos la impresión de ser una filosofía impregnada de un seductor carácter inactual, como síntoma claro del vigor que la recorre con voz propia. Nancy hace tambalear los cimientos de pensamientos asentados por la inercia de la tradición, nos abre los ojos, se despoja de las vestiduras y va por libre, libre de otras voces y libre de sí mismo. Se descarna de sellos que han dejado marcas en la cultura de Occidente para ser solo pensamiento que penetra en lo aprendido y des-aprende para, al mismo tiempo, ir solo con el equipaje necesario donde cabe la banalidad, el encuentro con los otros. Se posiciona fuera del ensimismamiento del pensar condicionado. En estas escuchas pongo oído a diversos temas nancyanos, sin pretender abarcarlos en toda su amplitud, como es lógico. Me asomo al tema del cuerpo al ser uno de los blancos a los que apunta el pensamiento de Nancy, el cuerpo que no es un cadáver diseccionado en una fría clase de anatomía ni es leído en tercera persona, el cuerpo que no es posible diseccionar en vida, ni trocearlo con el bisturí de un lenguaje que no termina de atrapar todos los «indicios» que lo conforman. Tumba de sueño es una reflexión sobre el sueño, sobre los procesos no medibles de ciertos registros que se dan en el extraño mundo del durmiente, no palpables a través de una tecnología que avanza pero que no se hace con verdades sino con móviles espejismos que Nancy señala:

De ahí que la mayor parte de las veces la filosofía se acabe presentando como un saber elitista que identifica sin más comunidad y pensamiento, como la puesta en obra continua de un ser-sentido común, donde se cortocircuita toda comunicación, donde la comunidad no se reconoce, y que solo es tolerada de forma irónica o despectiva por esa comunidad. De ahí, la desdicha de la filosofía, que comenta Nancy (en «El sentido significado»), incapaz de hacer que su mensaje alcance a sus destinatarios, es decir, a la comunidad de la que parece hablar ${ }^{1}$.

La actitud filosófica, podríamos decir generosa, de Nancy atrae hasta los contrarios porque su actitud no obliga, solo invita a pensar fuera de corsés acadé-

${ }^{1}$ Perera Velamazán, P., El tacto del pensamiento, ensayo que se incluye en El olvido de la filosofía, J.-L. Nancy, Madrid, Arena Libros, 2003, pp. 97-98. 
micos. Como cuando piensa la piel del cuerpo, el lienzo que envuelve y extiende la actitud de un artista que desea eternizarse en un cuadro, sin que por ello tuviera que estar presente esa intención en la primera pincelada. Asomarse a algunas de sus obras como A la escucha, 58 indicios sobre el cuerpo. Extensión del alma es ir en busca de una voz limpia, purificada, sin prejuicios, es abrirse a otra filosofía. Por otro lado, Nancy dedica tiempo a lo que sería la banda sonora de nuestro pensar occidental, de nuestra forma de estar en el mundo, el cristianismo. De la «desconstrucción del cristianismo" me ocuparé con más detalle en el último capítulo a modo de respuesta a esa trastienda que Nancy denuncia abiertamente, para señalarnos el límite que solo es posible vislumbrar pero no tocar en su totalidad. Porque Occidente es el heredero y el resultado final de un largo proceso que aún no termina, de un mundo latente que decae y se levanta, que alimenta pensamientos caducos, que se globaliza y deja dudas sembradas sobre esa entera y fragmentada globalidad.

\section{A LA ESCUCHA DE NANCY}

Estar a la escucha constituye hoy una expresión cautiva de un registro de sensiblería filantrópica en que la condescendencia hace eco a las buenas intenciones, a menudo, también, en una tonalidad piadosa... ¿qué es un ser entregado a la escucha, formado por ella o en ella, que escucha con todo su ser?².

Nancy desde los primeros compases lleva al lector al territorio exacto de la escucha referida. Se zafa de anteriores significados vinculados a la escucha como un lugar ubicado a la sombra, al acecho, en una escucha agazapada entre el follaje, como quien está a la espera, sigiloso, y desea hacerse con una información que luego puede ser usada con fines determinados. En esta escucha importa más lo sonoro que lo que puedan significar los sonidos codificados por la razón que todo lo da por sentado. Nos conduce a escuchar a pecho descubierto, sin filtrar por códigos la sonoridad de la voz humana o los matices más sutiles de un violín, de un piano, la vibración sin nombre de un violoncelo que se desborda para instalarse en lo que está por pensar, y así dudar hasta de la sonoridad de la propia escucha. Tiene para Nancy un gran valor el sentido del oído y hace parejas con «ver y mirar, oler y husmear u olfatear, gustar y paladear, tocar y tantear o palpar, oír y escuchar", como si estos emparejamientos dejaran entre sí un vacío libre de carga semántica, liberado de la codificación que todo lo sella. Este modo de escucha de Nancy es una de las pistas, a mi juicio, de su pensamiento porque lleva lo sabido a los bordes, su filosofía "es siempre estar a orillas del sentido o en un sentido de borde y extremidad" para afrontar los problemas y la estética actuales, y pone bajo sospecha lo representado. «Una escritora -nos dice Nancy en su obra $A$ la escucha- señala: 'Puedo oír lo que veo: un piano o el follaje movido por el viento. Pero nunca puedo ver lo que oigo.

2 Nancy, J.-L., A la escucha, Madrid, Ed. Amorrortu, 2007, p. 15. 
Entre la vista y el oído no hay reciprocidad'». Esta vuelta de tuerca es un esfuerzo por oír lo que está debajo, oculto en la representación visible o en los sonidos, es una escucha que cumple con la función despertadora de la filosofía que se implica con el presente y baja a las plazas para estar a la escucha a pie de obra:

La escritura también es, de manera muy literal y hasta en el valor de una «archiescritura», una voz que resuena. (Aquí sin duda, escritura literaria y escritura musical se tocan de algún modo: de espalda si se quiere. Se plantea entonces, para una y otra, la cuestión de la escucha de esa voz como tal, en cuanto no remite sino así: es decir, la escucha de lo que no está ya codificado en un sistema de remisiones significantes, y no entendamos sino lo ya codificado que decodificamos) $)^{3}$.

Nancy no solo busca instalarse en el desborde, sino que al emprender esta arriesgada incursión por los límites se encamina también a los orígenes, a un espacio virgen en el que ha crecido la maleza sin control, y donde los significantes y los significados no existen como tales por no rendir pleitesía a lo codificado. Es una continua vigilancia que invita a no bajar la guardia en el pensar. Y esta filosofía también la aplica Nancy no solo a la estética de lo sonoro -sea la voz humana, el ruido del viento o una melodía-, sino que también está presente como estrategia cuando extiende la mirada, o más bien el oído filosófico, a asuntos como la deconstrucción del cristianismo y la aniquilación de los textos evangélicos por estar vacíos de verdad, tema del que me ocuparé con más detalle más adelante. Nancy se ocupa también con buen tino de problemas que están latentes, en peligroso periodo de incubación, como son los brotes neonazis de nuestro tiempo, que recuerdan el horror «del exterminio programado de judíos»:

Con la convicción de que el presente no se ha liberado de sus vínculos con el pasado nacionalsocialista, El mito nazi, escrito junto a Lacoue-Labarthe (inicialmente en 1980, luego republicado en 1991), seńalaba el comienzo de una preocupación filosófica por las formas posibles de la repetición y de la identificación mítica que asedia la escritura nancyana y que la empuja hasta los límites mismos de sus (in) fidelidades teóricas con el pensamiento de Heidegger ${ }^{4}$.

Nancy se para en la reflexión de «las búsquedas estéticas más controvertidas, como la novela de Tournier (El rey de los alisios) o la película de Syberberg (de la que El mito nazi se declara explícitamente deudor)", según apunta Paula Fleisner en su ensayo La posibilidad del poema o 'los poetas no olvidan'. Nancy y el problema de la representación. Nancy cuando habla de representación el prefijo «re» no está asociado a una repetición a plena luz del día que insiste en lo que ya se dijo con anterioridad, sino, como apunta nuestro autor, «la representación no es la repetición de

3 Ibidem, p. 74.

${ }^{4}$ Varios autores, Jean-Luc Nancy: arte, filosofía, politica, Buenos Aires, Prometeo Libros, 2012, p. 67. 
una presentación, sino una presencia presentada, expuesta o exhibida, sacada de su inmediatez», en la representación está lo que no está presente:

Sigamos a Granel: de la melodía al silencio que la declara callando la unidad de su unidad y su diferencia, tal es el ascenso ultrafenomenológico, es decir, ontológico, siempre en el sentido de que el ser difiere allí continuamente de todo ser aquí y ahora... se trata de remontarse o abrirse a la resonancia del ser o al ser como resonancia. El «silencio», en efecto, debe entenderse aquí no solo como una privación, sino como una disposición de resonancia: un poco -y hasta exactamente- como cuando, en una condición de silencio perfecto, uno oye resonar su propio cuerpo, su aliento, su corazón y toda su caverna retumbante .

Nos recuerda la caverna platónica como el lugar de las sombras, de los reflejos, pero también el sonido de las voces, aunque la primacía se ha apoderado de lo visual en detrimento de este aspecto sonoro que Nancy destaca, donde el sujeto observa el fenómeno como algo que le es ajeno. Sin embargo, aquí resuena también el sujeto desde el vientre materno como una entidad implicada en la resonancia, no como un espectador que mira y siente en tercera persona:

La escucha musical aparece entonces como la muestra, la elaboración y la intensificación de la disposición más tensa del «sentido auditivo». (La escucha musical quiere decir, a fin de cuentas, la música misma, la música que, ante todo, se escucha, sea escrita o no y, cuando lo es, desde su composición hasta su ejecución. Se escucha de acuerdo con las diferentes flexiones posibles de la expresión: está hecha para ser escuchada, pero es ante todo, en sí, escucha de sí) ${ }^{6}$.

Nuestro autor rompe con términos familiares en el ámbito filosófico como ser, comunidad, cuerpo, etc., para volverlos a pensar:

De este modo, de repente y a partir de ahí, nos encontrábamos con Nancy tratando de pensar todas esas "palabras increíbles», los grandes conceptos de nuestra tradición que él vuelve a poner en circulación con miras a una nueva invención, porque Nancy no «retoma» esos conceptos, sino que los crea ex nibilo...?

Es un borrón y cuenta nueva lo que plantea Nancy, es una renovación de palabras agotadas, de conceptos, que demandan una escucha y una lectura que ponga al día otros modos filosóficos:

Cómo lo invisible se deja ver en lo visible, el modo en que un inconmensurable se transforma en nuestro nuevo valor de medida y la manera en que la finitud no

\footnotetext{
5 Nancy, J.-L., A la escucha, p. 45.

6 Ibidem, p. 55.

7 Rodríguez Marciel, C., Nancytropias, Madrid, Editorial Dykinson, 2011, p. 25.
} 
acota la infinitud, sino que le da su expansión. Por lo demás, con el hiperbólico anuncio de una filosofía por venir... ${ }^{8}$.

Apunta Cristina R. Marciel en su Nancytropias, como uno de los rasgos más destacados del estallido de Nancy, que es posible pensar «una filosofía después de la filosofía». Si nos ponemos a la escucha de Jean-Luc Nancy,

es más plural en su singularidad que cualquier otro. A poco que nos acerquemos a sus textos podemos darnos enseguida cuenta de lo poco que tienen sus «obras» en sentido clásico y lo mucho que hay en su trabajo de colaboraciones, intercambios, reenvíos, remisiones y puestas en común'.

Porque el despliegue que desarrolla en sus variadas publicaciones remite a una unidad que vertebra su pensamiento y da un sentido que nos remite a un espacio desde donde otra vía de acceso hacia un nuevo sentido pide paso porque, como apunta Rodríguez Marciel, «ya no se trata de interpretar el mundo, sino de transformarlo». Es, por tanto, una filosofía de la acción que no se conforma con quedarse en el graderío viendo cómo pasan los acontecimientos, si bien esta trasformación no va asociada a un papel «operativo» de la filosofía en el mundo, sino que se trata de "cambiar el sentido del sentido» en palabras de Nancy. Esto no se resuelve con una filosofía del retorno que vaya al momento exacto donde las encrucijadas digan hacia dónde fue cada uno por si fuera posible reconducir el presente con los ojos del pasado. Nancy critica «el esquema del retorno» como linterna amparada en un regreso que pudiera iluminar a Occidente en busca de su único sentido, el sentido que siempre aparece como marca de los próximos pasos.

\section{LA NOCHE DE LOS PÁRPADOS}

La noche de los párpados es preludio del sueño, es la caída en la negrura del sueńo, en el oscurecimiento de las formas y los colores. La noche, a la que Nancy atribuye una igualdad constante, pone la alfombra al sueño para que camine sin dar cuenta de lo que reclama la vigilia que distingue los días, la vigilia que es la condición que antecede a la caída en el sueño. Nancy en su libro Tumba de sueño nos recuerda que el centinela lucha por no caer vencido por el sueńo, que llega, «se impone, extiende su influjo y su sombra con la discreción y la constancia característica del anochecer, el polvo, la edad $\aleph^{10}$. En el sueño el durmiente se alimenta de sí mismo, le basta con sus propias reservas alimenticias, «hambre con reposo es alimento", dice el dicho popular.

\footnotetext{
8 Ibidem, p. 27.

9 P. 28.

${ }^{10}$ Nancy, J.-L., Tumba de sueño, Madrid, Ed. Amorrortu, 2007, pp. 12-14.
} 
«Quien duerme, come», dice Nancy. Caer en el sueño es caer derrotado por lo que se ha hecho en un trabajo físico o intelectual, por el agotamiento apasionado de los amantes, por el cansancio de la angustia. La simultaneidad temporal que Nancy atribuye al sueño hace posible una especie de eterno presente, una «copresencia» donde lo compatible convive con lo incompatible, donde las rupturas oníricas no parecen alterar la lógica de quien duerme, de un yo que aparece estampado en un film poblado de pesadillas o de sueños posibles. Un yo que se ve a sí mismo mientras tiene los ojos cerrados. Un yo que se diluye porque «me caigo de sueño, es decir que 'yo' caigo, que 'yo' ya no soy o bien que 'yo' ya no 'es' más que en esa borradura de su propia distinción ${ }^{11}$. La identidad en el sueño carece de referencias que afiancen el yo, porque el yo se introduce donde no parece clara la distinción del durmiente con la escenografía de la que también forma parte, porque la mirada de la vigilia ha sido sustituida por unos ojos que miran hacia dentro:

Si sueńo con acciones y palabras en las que soy el sujeto, lo hago siempre de tal modo que esa subjetividad no se distingue o se distingue mal, al mismo tiempo, de lo que se ve, oye y percibe en general ${ }^{12}$.

La caída en el sueño para Nancy no es un desplome de la conciencia sino la entrada en una inconsciencia consentida que se escapa a toda comprensión definitiva, el «sí mismo durmiente» no se presta a ser atrapado en una fenomenología del sueño que deje distinguir entre «el ser y el aparecer»; porque el sueño «al fenomenólogo despierto que se acerca a su cama ya no le deja percibir más que la apariencia de su desaparición, el testimonio de su retirada $»^{13}$, los últimos instantes de la vigilia. El durmiente se iguala a otros durmientes y el sueño también supone un océano donde la igualación aparece dominada por el silencio y la oscuridad:

Las noches bien pueden diferir entre sí hasta llegar a la oposición de la noche de insomnio y la noche sellada bajo un sueńo de plomo. Pueden exhibir los contrastes de las lámparas encendidas y los fuegos apagados, de las fiestas nocturnas y las casas dormidas: no por ello dejan de ser la noche, la noche siempre recomenzada. Los días, por su parte, bien pueden agruparse en la monotonía más repetitiva, en lo cotidiano, cuyo nombre significa "tantas veces el día y tantas veces lo mismo»: no por ello cada día deja de contrastar con los demás, como una luz difiere de otra y una sombra de otra ${ }^{14}$.

El sueño es divino, dice Nancy, porque en él queda suspendida «la palabra creadora», en una noche que sorprende a quien duerme por una infinitud intuida, sin paredes fijas, sin bordes que marquen los contornos de una realidad que sí parece más marcada en el trascurso de los días que se repiten en un escenario con diver-

\footnotetext{
${ }^{11}$ Ibidem, p. 20.

12 Ibidem, p. 20.

13 P. 25.

${ }_{14}$ P. 34.
} 
sos actores, con otras músicas y pasiones. Nancy asegura que lo que el durmiente es capaz de captar es «esa cosa eclipsada... no la corona de llamas que lo bordea», el borde de otro borde, tal vez una frontera que no se percibe ni en la vigilia ni en el sueño con toda su redondez:

No hay parte de lo visible y tampoco, por consiguiente, de lo invisible. Ya no hay división ni partición. Nada de lo que podría venir de afuera o escapársele, ninguno de los supuestos 'mensajes' o de los pensamientos, sean del ojo o del oído, de la nariz, de la boca o de la piel, de los nervios, de las vísceras... ${ }^{15}$.

Es un hermético territorio que solo se abre y se cierra con la entrada o a la salida al mundo de los sueños, cuya puerta parece estar cerrada a cal y canto y vigilada por un Cancerbero de innumerables cabezas. Quien deja la vigilia para dejarse inundar por el sueño cierra una puerta tras de sí, y quien despierta también deja a sus espaldas un portón. Nancy ve en el despertar el aroma del sueño todavía, las brasas aún tibias de lo sońado, rastros de la nada dormida, secuencias sońadas y pintadas con colores saturados,

pero cuya consistencia espesa se enturbia y se desintegra de manera precipitada en la acidez del día e incluso en la fantasía o en los fantasmas de la interpretación que, para terminar, se pierde con mucha regularidad y necesidad en el subsuelo de ese ombligo del sueño del que Freud habla para destacar que todo ocurre aquí antes del nacimiento, con anterioridad a cualquier distinción y cualquier separación, cualquier discernimiento de persona y de sentido ${ }^{16}$.

Una vez más nuestro autor piensa lo que parece estar ya pensado en la mitología antigua, en la ciencia, en la neurología, en las ondas cerebrales que leen los ritmos del sueño y, sin embargo, abre otros interrogantes en busca del sentido. Ve señales en el sueño, destellos que responden con intermitencias que no terminan de ser respuestas. Cuando un cuerpo duerme, otros cuerpos pueden ver que duerme, que respira al compás de la inconsciencia, que abandona la realidad que se ve en los objetos para introducirse en un viaje sin itinerario marcado y del que no parece posible dar una crónica detallada, tras el regreso a la vigilia. Una vigilia que duerme y vela el sueño del durmiente y vigila la vigilia del despierto. Sin embargo, el alma es la reina de la vigilia porque está despierta mientras el cuerpo permanece despierto y cuando las brumas del sueño la llevan a otros reinos:

Jamás, sin embargo, jamás duerme el alma. Ese ausentarse de sí en sí le es desconocido. Perteneciente al cuerpo y el espíritu, es ajeno al alma. En el dormir, el espíritu se abandona al cuerpo y dispersa en él su puntualidad, disuelve su concentración en esa extensión blanda y casi desarticulada ${ }^{17}$.

15 P. 39.

16 P. 41.

17 P. 51. 
Incluso el cuerpo pasa a ocupar «un no lugar» alejado del mundo porque el hombre que permanece dormido es «un cuerpo espiritual»o «un espíritu corporal», con un alma que no es un "piloto» que conduce una nave, sino que se manifiesta en el cuerpo en su totalidad. La noche es el momento del sueńo por muy iluminada que esté, la noche es el reino de la oscuridad, porque iluminar no es más que disfrazar la oscuridad, matar tramos lumínicos, taparla para que sea delatada por las sombras. La sombra que tantas veces es puesta en lo más alto de su valor estético por el escritor japonés Tanizaki, que desprecia la luz cenital de las bombillas occidentales en su Elogio de las sombras porque deforman la belleza de los cuerpos, de los objetos, del espacio que habita en las estancias iluminadas por la luz que se filtra a través del papel de arroz. La luz cenital occidental es despreciada por Tanizaki porque el exceso de luz recalienta las cabezas y mata las luces rasantes que embellecen la vida. La noche que da lugar a las sombras es para Nancy el lugar natural de los miedos. «Las ambulancias desgarran la noche, y los cañones, y los disparos de misiles, el llanto de los nińos...." ${ }^{18}$, la noche alienta las obsesiones en un mundo que Nancy piensa que está dormido y de pie, un mundo que vive sin posar la cabeza en la almohada del descanso y la reflexión, «sin sueño ni vigilia»:

El dormir y el sueńo apenas han interesado a la filosofía que ha interpretado casi siempre el sueńo como el descanso de los héroes y guerreros, transformándolo en un reservorio en el que acotar y mantener controlado el germen de la fatiga y del cansancio para una vez vencidos éstos comenzar un día siguiente rebosante de fuerza y frescura ${ }^{19}$.

El sueño ha quedado a merced de otros lenguajes. Se ha acomodado como en casa tanto en la poesía como en la psicología. En la psicología se ha pretendido leer los desajustes de la vigilia desde el sueño, resolver lo que surge en la nebulosa de las pesadillas a la luz del sol de los días:

Un cuerpo dormido, un cuerpo muerto: evanescencia y presencia donde no hay afuera ni adentro, en todo lo largo del plano, en la extensión de su postración. Por eso no hay fenomenología del dormir, dice Nancy. El durmiente sólo muestra la superficie de su desaparición, el escaparate de su abandono al sueño ${ }^{20}$.

El sueño y el durmiente en esos momentos constituyen, si se quiere, un enigma; porque quien duerme se ve despojado de la visión dual de la realidad con la que tiene que habérselas en la vida cotidiana. En el sueño ya no hay un observador que mira y hay algo que es mirado, el yo se disloca en un espacio que no es traducible. La dualidad observador-observado palidece en el sueño para traducirse en otro lenguaje, en otro mundo que tal vez sea el mismo mundo o la antesala de otro. En

\footnotetext{
18 P. 55.

19 Rodríguez Marciel, C., Nancytropias, Madrid, Editorial Dykinson, 2011, p. 346.

20 Ibidem, p. 349.
} 
esto Nancy se ha tirado a la piscina, a la Tumba de sueño, para deshacer tareas anteriores que han pensado con otras claves lo que nos queda delante de nuestras narices:

Por ello, nada dice, porque nada tiene que decir, el pensamiento de Nancy, salvo su acaecer, como pensamiento sin más, desnudo, hurtado a sí mismo, despojado de los ropajes del conocimiento y el saber, que no es Concepto, que no es Idea, que no es Filosofía, pero tampoco Meditación o Pensamiento sin más, ni reflexionante, ni especulativo ni reductor, ni hermenéutico, despojados de las vestiduras de la identificación y el destino ${ }^{21}$.

Nancy se atreve con el sueño y se abre a nuevas incertidumbres donde el sueño deja de ser individual para ser esa fiesta en la que coinciden durmientes y sueños, sueños de paredes flexibles que lindan con otros sueños situados en el borde de otro mundo que está a la espera de sentido.

\section{EL ARTE Y EL MUNDO}

El título del artículo de Nancy, «El arte de hacer un mundo» denota en español hacer de algo insignificante algo extremadamente desmesurado, que salta las vallas de lo que la norma dicta, un mundo que proclama su atomización. Desmembrado en su naturaleza, se nos da una imagen del mundo unitaria, que no da cuenta de la fragmentación de la que habla Nancy. «Sufrimos por un mundo donde una de cuyas partes puede explotar a otra, o cuyos valores monetarios y técnicos son todos convertibles mientras que los valores morales y jurídicos pueden entrar en grave conflicto ${ }^{22}$. Con lo que se ve que moral y valores monetarios van por diferentes carriles, la vida humana tiene un valor concreto en una zona del planeta y en otra no es más que una cifra, en el mejor de los casos, o un cuerpo que es abatido por un mísero modelo de justicia. Esto que denuncia Nancy se enfoca hacia la valoración de las personas sin esos saltos que dejan lagunas en el reconocimiento efectivo de la dignidad humana. "Es del valor único e inconmensurable de cada existencia que un mundo está hecho, no de la sumisión a alguna medida supuestamente dada desde otro lugar que de ese singular de los existentes ${ }^{23}$, donde se respeten los derechos de cada persona, sin estar condicionados por la nacionalidad, procedencia, situación moral, sus creencias en el plano religioso o el sexo en este panorama en el que la mundialización se sitúa, también, ante la mirada de Nancy. El mundo y el arte. Dos elementos que se relacionan en su totalidad. El arte, según Nancy, no tiene vínculo con la historia ni con eso que llamamos verdad, ni le atribuye una trascendencia metafísica que puede confundirse con lo religioso, el arte como porta2012, p. 13

21 Perera Velamazán, P., op. cit., p. 86.

${ }^{22}$ Varios autores, Jean-Luc Nancy: arte, filosofía, politica, Buenos Aires, Prometeo Libros,

23 Ibidem, p. 13. 
voz de un mundo trascendente admitido como consuelo. Elementos que no hay que desordenar en la mesa de trabajo porque nos servirán para entender otras parcelas del pensar nancyano, como la invitación a deconstruir el cristianismo, por ejemplo, desde sus propias raíces. El arte se relaciona directamente con el mundo, a él dirige sus mensajes y de él recoge la resonancia de la sonoridad enviada desde una composición musical, una instalación artística o una tela impregnada de emociones. Es en la unidad aparente e «impresentable» del mundo en la que Nancy detecta su fragmentación. «Porque la unidad del mundo nunca había sido más que la unidad proyectada sobre él por tal o cual pensamiento, tal o cual cultura, y en primer lugar la cultura de Europa ${ }^{24}$. El mundo que podemos representar ya no sería mundo, sería un fragmento de nuestra creación, aislada del resto y que de ninguna manera puede englobar al mundo. El mundo es "el medio donde uno se encuentra", no es el paso de la «universalidad» a otro concepto, «la pluriversalidad», que habla de una realidad múltiple. Nancy asegura que un sentido como representación última del pensamiento haría aguas porque siempre habría otras posibilidades de pensamiento, «el mundo es acósmico" y no necesita un poder ordenador de carácter teleológico. No se necesita un Dios religioso que acoja las peticiones y que no es un «principio ontológico», según Nancy. "Un mundo es ahí donde todo está apud todo: todo está cerca de todo, todo tiene lugar, pero Nada hace un Todo. Y este 'no hacer un Todo' es justamente lo que hace ser o deja ser... ¡todo! $»^{25}$. Una mundialización que es capaz de parir un arte nivelado en diversos puntos del planeta, y que tiene como una de sus causas la simultaneidad informativa, que genera ahora más que nunca pensamientos, productos e inspiraciones artísticas similares en diversas partes de nuestro mundo. La cultura succiona el arte como un elemento dispuesto a dejarse administrar y se manifiesta también en una individualización institucionalizada de la que es muy difícil escapar. Lejos de lo que Nancy apunta cuando afirma que

el arte en la época de la mundialización tiene por tanto la carga de testimoniar del mundo en cuanto mundialidad que lleva, desvía o esconde la unidad de un cosmos o de un mundo-objeto (de una "naturaleza») tanto como de un mundo-sujeto (de una «historia»). Es esta verdad la que queda por pensar y por trazar, en su retiro y a partir de su retrazo.

Una verdad que Nancy relaciona con el pensamiento y la obra. Y a su vez, «el pensamiento se relaciona con el retiro (o el retrazo, retrait) de la verdad, la obra se relaciona con el trazado (tracé) de la verdad», en este arte que siempre debe reservarse significaciones ocultas, información retenida que dará siempre lugar a significados abiertos a una interpretación múltiple. Según Nancy:

La mundialización espera su gran arte: el arte de hacer un mundo global abierto sobre lo inadecuado, sustraído a la dominación de un principio o de un fin (como

24 P. 14.
25 P 19. 
el dominio técnico y económico). La mundialización debe ser ella misma un arte, y un pensamiento... ${ }^{26}$.

Que estaría por llegar, parece indicar nuestro autor, al tiempo que convoca un arte unido a lo «inadecuado» como garantía de estar cercano a lo «verdadero». Lo inadecuado, lo rebelde, lo que se enfrenta por definición a la corriente establecida, «lo inadecuado por excelencia»:

Pensamiento y obra giran hacia lo inadecuado, abren la relación con lo inadecuado en cuanto tal, y en consecuencia, se encuentran de entrada en una situación distinta a la de brindar una idea o una imagen adecuada... Tampoco se trata de aproximación ni figuración. Se trata de poner en juego la imposibilidad de la adecuación (del sentido y al sentido) ${ }^{27}$.

Por tanto, el mundo sería el reflejo claro de la verdad por llevar consigo y ser portador de lo inadecuado en su más alta expresión, al escapar a cualquier molde de adecuación.

\section{EL CUERPO HABLA Y NOS POSEE}

El cuerpo ocupa un lugar primordial en el pensamiento de Nancy, sus reflexiones van más allá de una visión inmanente del mismo como aparece en la ontología spinozista; rompe con el discurso cartesiano de la res extensa y la res cogitans que sigue instalado en nuestra realidad. Critica el clásico planteamiento que enfrenta las dos sustancias como dos mundos separados en su constitución, la matérica concreción de lo material y la inmaterialidad supuesta de un alma que a veces es suavizada con el término mente. Nuestro autor cuando habla de cuerpo no habla como una parte exterior que sirve de estuche a otra materia no medible ni visible, que es el alma. En 58 indicios sobre el cuerpo. Extensión del alma, Nancy desarrolla gran parte de su ontología modal sobre la corporeidad. Recoge improntas, estampas inspiradas y fugaces - a veces inconexas- de lo que es el cuerpo en relación directa con un ego al que le da soporte.

«Por esta razón, Nancy nos sugiere pensar el cuerpo como corpus: una unidad imposible de establecer más allá de las diferencias y contrates que involucra, y formalmente no es más que el interrogante acerca de sí misma ${ }^{28}$. Una unidad que se nos hace legible a través de "vestigios» que siempre nos darán una aproximación imprecisa y no definitiva, dispersa, sin una imagen global que pueda calmarnos la curiosidad, porque el cuerpo «nos posee, nos molesta, nos cansa, nos fastidia y nos

26 P. 21.
27 P. 20.
28 P. 93. 
rechaza ${ }^{29}$. Somos el cuerpo. El cuerpo ha sido pensado en la historia de la filosofía bajo diversos supuestos, también ha sido odiado, ignorado y puesto en cuarentena y sin acceso filosófico. Ha sido el envoltorio del alma, su tumba; el cuerpo es el castigo del alma que aún no ha volado a la morada de los elegidos. Al espíritu como contrario de lo físico, se le ha atribuido una cualidad que lo pone en sintonía con un mundo trascendente donde el cuerpo tiene negada la entrada. La corporeidad es la inmanencia que niega toda trascendencia a la condición humana, aunque a través de cuerpo algunos pensadores creen tener resuelta la misteriosa creación de los mitos, de las creencias religiosas; por entender que toda esta constelación creadora es el resultado del cerebro y de sus conexiones neurológicas sin más, que tarde o temprano cristalizan en el arte o las diversas manifestaciones culturales. También representa el cuerpo una nueva manera de estar en el mundo sin frenos morales que atenúen los impulsos que suman potencia a nuestras acciones.

Lo que hace Nancy es que atomiza el cuerpo sin parcelarlo, sus flases dedicados al cuerpo en 58 indicios... son instantáneas que no solo captan una imagen corporal para analizarla como un trozo aislado. Nancy nos da a entender que en esa aparente desconexión de las partes se halla la conexión interna de lo que llamamos cuerpo. Levanta la voz y reclama para el cuerpo una filosofía que no se agota. Según Nancy el cuerpo no conoce, solo siente; parece ironizar sobre lo ya sabido sobre nuestra corporeidad o con lo ya dicho por la neurociencia para ir al borde de lo que se sabe y plantar nuevos interrogantes, nuevos hitos que se desdibujan a lo lejos. No deja espacio a quienes atribuyen al hombre una trascendencia que se zafa de lo físico para instalarse en el territorio donde se fabrican los mitos, las esperanzas de una vida no material y, al mismo tiempo, hace palidecer el suelo que sostiene las creencias religiosas que miran con optimismo hacia el otro mundo. El alma también es material, según Nancy, y parece hacer esta afirmación con cierto matiz orientalizante cuando dice que el alma está hecha de un material más sutil, como si fueran los átomos ligeros de Demócrito; el alma, por tanto, está compuesta por una materia que es menos burda que la materia que forma el cuerpo que nos trae ecos neoplatónicos que hablan de la materia como el último eslabón de la degradación.

Igualmente, Nancy acaba con la dualidad cristiana que nos dibuja un cuerpo y un alma; un cuerpo que se corrompe en este mundo acosado por los males amenazadores del pecado, por las leyes naturales, y un alma que pasa a un plano donde es consciente de su propia individualidad; al contrario de otras creencias que aceptan y persiguen que el yo se diluya después de la muerte y en ese no-ser encuentran la justificación de la vida y el fin de las penosas reencarnaciones. De un plumazo Nancy pone en entredicho la tradición dualista que ha viajado a lo largo de la historia de la filosofía, desde Platón al propio cristianismo. Nancy hace trizas la exclusividad de aquellas disciplinas como la sociología y la psicología, que se han apropiado del lenguaje para explicar asuntos que piden con insistencia nuevos horizontes interpretativos. Merece especial mención el trato que da nuestro pensador a

29 P. 94. 
la piel, desde una arista interpretativa muy singular. Nancy da una visión de la piel de extrema importancia:

El cuerpo, la piel: todo el resto es literatura anatómica, fisiológica y médica. Músculos, tendones, nervios y huesos, humores, glándulas y órganos son ficciones cognitivas. Son formalismos funcionalistas. Más la verdad, es la piel. Está en la piel, hace piel: auténtica extensión expuesta, completamente orientada al afuera al mismo tiempo que envoltorio del adentro, del saco lleno de borborigmos y de olor a humedad ${ }^{30}$.

Porque la piel es el órgano más extenso del cuerpo, la piel nos pone en contacto con el frío y el calor ambiental, es la más extrema y externa expresión de nuestro yo, el envoltorio que nos distingue de otros cuerpos que vemos o tocamos. Nuestra piel puede desarrollar patologías si no sintonizamos con otros cuerpos, con entornos que percibimos hostiles en el afuera, es nuestra toma de tierra, con la piel tocamos el mundo y nos afirmamos en él. La piel «toma el sol, el frío y el calor, el viento, la lluvia, inscribe marcas del adentro ${ }^{31}$, dice Nancy porque la piel da pistas del «adentro» donde habita «alguien» que puede que esté «ahí», muy cerca; o puede que el «cuerpo indicial» esté dando señales de un alguien que está «bastante lejos», más lejos de lo que creemos. La ontología modal del cuerpo nancyano es todo menos una fría descripción del cuerpo, es una filosofía que viene de vuelta, de saber lo que se sabe, que entona un canción que acaricia el «Cuerpo tocado, tocante, frágil, vulnerable, siempre cambiante, huidizo, inasible, evanescente ante la caricia o el golpe, cuerpo sin corteza, pobre piel tendida en una caverna donde flota nuestra sombra.... ${ }^{32}$. Un cuerpo lo es en la medida en que se refleja y reafirma en otros cuerpos, que comparte con otros la estancia en el mundo, sujeto a leyes comunes que no pueden eludir, escurridizo para los lenguajes que pretender apropiarse de las múltiples caras de la verdad:

Agotar el discurso en y por la escritura se presenta aquí como un recurso contradictorio del pensamiento para tocar el cuerpo. No para mostrarlo y menos aún para demostrarlo ya que el cuerpo es evidente, sino para exponerlo, para inscribirlo fuera del discurso. En principio esto supone escribir el cuerpo hasta volverlo, según la palabra creada por Nancy, completamente «excrito», es decir, ajeno a toda significación, inscripción, marca o escritura ${ }^{33}$.

Una vez más, Nancy sitúa el cuerpo, que es nuestra forma visible de estar en el mundo, en el filo de los lenguajes, en una declaración de impotencia, al no poder llegar con los dedos del tacto a lo inaccesible. Porque, como apunta Daniel Álvaro:

${ }^{30}$ Nancy, J.-L., 58 indicios sobre el cuerpo. Extensión del alma, Buenos Aires, Ediciones La Cebra, 2007, p. 32.

${ }^{31}$ Ibidem.

32 P. 33.

33 Ibidem, ensayo de Daniel Álvaro, «Un cuerpo, cuerpos», p. 55. 
«Nada parece menos sustraído a la posibilidad del tacto, a la posibilidad de tocar y de ser tocado, que un cuerpo ${ }^{34}$, que comparte lugar, espacio, finitud y un afuera siempre arriesgado, porque se expone a otros cuerpos con los que se relaciona navegando en una extrañeza en la que convive en comunidad con otros cuerpos. Con otros modos que llevan a repensar la comunidad compuesta por otros cuerpos, algo de lo que no se puede huir.

Según Nancy, la pregunta por el cuerpo está ligada desde su génesis a la clásica dualidad entre el cuerpo y el alma de cuño platónico-cristiano; dualidad hasta tal punto decisiva en la configuración de los discursos occidentales que aún hoy parece difícil pensar el «cuerpo» sin oponerlo del modo más natural al «alma» o al «espíritu» $\aleph^{35}$.

El cuerpo como objetivo filosófico y excusa de multitud de discursos en diversos planos de la existencia humana, porque se quiera o no se quiera, pensar el cuerpo ha tenido y tiene consecuencias en los hilos que trenzan la urdiembre de los discursos, los discursos de índole política, religiosa o ética:

Por el contrario, para Deleuze, el lugar donde se juega el sentido de un cuerpo no es el ego, en el sentido particular de este término que sugiere Nancy, sino el campo de la etología, redefinida en términos dcl estudio de los afectos ${ }^{36}$.

Porque el cuerpo humano no es diferente como materia a otros cuerpos que pertenecen a otro tipo de seres, de animales irracionales o a otras formas de vida, que están igualmente bajo el mando de las leyes de la naturaleza; y el hombre como ser inserto en ella se ve preso también de las pasiones, de afectar y ser afectado por otros cuerpos. El cuerpo humano puede verse afectado por la tristeza y el odio, que restan potencia, o puede sentir alegría, que siempre sumará potencia como resultado ideas adecuadas, como refleja el pensamiento de Spinoza, uno de los inspiradores de los trabajos nancyanos sobre el cuerpo. Otro de los conceptos que tienen que ver con la filosofía del cuerpo de Nancy es la exposición:

Un ejemplo de esta dinámica de la exposición se halla, según Nancy, en la escucha. Escuchar significa entrar en una espacialidad desde la cual al mismo tiempo se es penetrado. En el acto de la escucha, la espacialidad se abre en uno tanto como alrededor de uno, y a partir de uno como fuera de uno ${ }^{37}$.

Y en esta escucha está implicada la piel como receptora de lo que es el mundo, en su sonoridad. Como señalan Cecilia Cozzarin y Alejandro Simón Lopez, en su
${ }^{34}$ P. 57.
35 P. 63.
${ }^{36}$ Varios autores, Jean-Luc Nancy: arte, filosofía, politica, Buenos Aires, Prometeo Libros, 2012, p. 94.

37 Ibidem, p. 97. 
ensayo El cuerpo entre Nancy y Deleuze, "la música como resonancia entra y dilata el cuerpo", que no le queda más remedio que ponerse a la escucha al ser la música la manifestación de una excedencia. «Esta excedencia es la dimensión ontológica de la desnudez del cuerpo e indica un 'desvestirse del pensamiento'", que ya no busca obsesivamente significados sino «aquello que se menciona como el abandono de los dioses o la caída del fundamento» ${ }^{38}$.

\section{LA DESCONSTRUCCIÓN DEL CRISTIANISMO}

Desde las primeras líneas de su obra La desconstrucción del cristianismo, Nancy deja claro que el cristianismo se empieza a «desconstruir» desde sus propios orígenes. Tal vez en este deshacerse a sí mismo en tiras se halle una de las claves más destacadas de la supervivencia de este acaparador cultural, moral, teológico y de poder que es el cristianismo y todo el hermético edificio de creencias que lo acompaña. Porque justo en ese saber del movimiento de las sociedades, de los momentos que sonríe la suerte, y del mudar constante de la estancia de los hombres en la mundaneidad, encuentra quien ejerce el poder una de sus mejores armas para eternizarse en posiciones de privilegio. Pero lo que habría que preguntarse es cómo este telón de fondo que ha visto y ve pasar la historia que es el cristianismo ha durado tanto en escena, con diversos actores en la boca del escenario, con guiones diferentes a lo largo de la historia. Después de tantos siglos, resulta impensable que el cristianismo encierre en las entrañas de su comienzo la intuición del futuro tan largo que le esperaba, y que sea la herencia interesada de un grupo de hombres que se reunió en torno a un maestro.

Sin embargo, justo es esto lo que no produce extrańeza en el creyente, que este grupo tan corto de seguidores, solo eran doce apóstoles, haya prendido una llama de tal intensidad que su fuerza permanece viva hasta nuestra epocalidad. El resto son rescoldos esparcidos por el planeta que se avivan o atenúan en su resplandor según sea la intensidad de los vientos del momento, y cuya presencia llega no solo a Occidente, sino hasta el último rincón de la Tierra. La crítica al cristianismo desde la razón que plantea Nancy nos llevaría sin remedio hasta los límites del pensar, hasta la trastienda de lo pensado hasta ahora, hasta territorios fronterizos donde la filosofía como reflexión humana podría perder el nombre. Nancy, amparado e influido como es lógico por su ontología del cuerpo, quiere saber qué hay más allá de esta realidad occidental que se sustenta sobre los pilares del cristianismo, qué cimientos han soportado el peso de tantos siglos de veneración de hombres y mujeres que se han visto en la ineludible circunstancia de vivir en el cristianismo, fueran creyentes o ateos. Nancy mete el dedo en la llaga y no se queda en la periferia, en una mirada superficial, diseña un plan que se traduce en una hermenéutica que toma carácter según avanza en búsqueda de respuestas. No es una crítica desde la 
superficie lo que plantea Nancy, desde la orilla, sino que ataca el problema y se pregunta sobre una ontología cristiana que ha sido aceptada mansamente por creyentes, y cuyos supuestos no parecen sostenerse bajo la mirada de la filosofía. Pero lo cierto es que se sostiene y se ha sostenido desde hace mucho tiempo, más de dos mil ańos. Nancy quiere llegar a los entrebastidores del tiempo transcurrido. Quiere saber qué había antes de que la linealidad temporal cristiana se instalara en Occidente con los ojos puestos en la escatología cristiana, a la espera de una vida donde los cuerpos quedarían revestidos de luminosa espiritualidad.

No es tarea fácil tratar de agarrar el cristianismo desde la razón sin que se te diluya entre los dedos como si fueran los peces crísticos que adornan las catacumbas de los orígenes cristianos. El cristianismo ha sabido leer los momentos y acomodarse al pensar de cada uno de esos momentos, característica que pensadores como Maquiavelo destacan al considerar que estas dos vertientes de la acción humana, la fortuna y la virtud combinadas en el momento adecuado, constituyen una poderosa aleación capaz vencer todos los obstáculos y que cuando se saben congeniar llevan al éxito en asuntos de poder. Por otro lado, y mientras se piensa en la desconstrucción del cristianismo, desde el epicentro del catolicismo, hoy se fomenta una nueva evangelización ante el descenso de fieles en los templos que se une al desencanto de una fe perdida y al ascenso de otros ídolos, entre los que destaca el dinero como un dios que nunca será compatible con la esencia evangélica. Esta nueva evangelización es una clara manifestación de que hoy estamos asistiendo a una nueva forma de deconstrucción del cristianismo: se ponen en entredicho contradicciones internas de índole moral, se apuntan cambios en la liturgia en los modos de vida del sacerdocio y se suma, además, el reconocimiento de errores históricos cometidos por la Iglesia católica. Esto, que puede verse como un claro y paulatino decaimiento del cristianismo, quizá sea un signo que, desde la escucha filosófica, sea conveniente no perder de vista ni un instante. Una escucha que se me antoja sana porque

de suponer que aún tiene sentido plantear interrogantes sobre los límites o sobre unos límites de la filosofía (de suponer, por tanto, que un ritmo fundamental de ilimitación y limitación no constituye la andadura permanente de dicha filosofía, con una cadencia variable, quizás hoy acelerada), preguntaremos esto: ¿̨la escucha es un asunto del que la filosofía sea capaz? ¿O bien -insistamos un poco, pese a todo a riesgo de apelar al trazo grueso- la filosofía no está adelantada y forzosamente ha superpuesto a la escucha o la ha sustituido por algo que es, más bien, del orden del entendimiento? ${ }^{39}$.

Una escucha que no es solo necesaria para hacerse con los ruidos del presente, sino para percibir qué melodías han cruzado Occidente sin que se haya visto alterada la velocidad de crucero del cristianismo, y más en concreto el cristianismo católico; es por eso por lo que Nancy se da herramientas a sí mismo cuando dice:

39 Nancy, J.-L., A la escucha, Madrid, Amorrortu, 2007, p. 11. 
Queremos aquí aguzar el oído filosófico: dar al filósofo un tirón de orejas para tenderlas hacia lo que siempre interpeló o representó menos al saber filosófico que lo que se presenta a la vista -forma, idea, cuadro, representación, aspecto, fenómeno, composición-, y que se eleva más bien en el acento, el tono, el timbre, la resonancia y el ruido ${ }^{40}$.

La escucha nancyana reclama la presencia de un oído filosófico que ha permanecido hasta ahora atrofiado por haber dado prioridad a otros objetivos más externos, más visuales; propone otro enfoque, una lectura más rica que aclare las lentes con las que hemos mirado a Occidente hasta ahora: «El cristianismo es inseparable del Occidente: no es ni algo accidental que le sobreviniese a Occidente (para bien o para mal) ni trascendente a él. Es coextensivo al Occidente en cuanto a Occidente». Nancy echa por tierra, por tanto, el cristianismo en su valor trascendente, el Dios que pregona la fe cristiana no es necesario para explicar el mundo, su existencia no se plantea ni justifica la estancia del hombre en el mundo. Es como si Nancy saltara del patio de butacas y no se conformara con pisar el escenario donde transcurren las preguntas; su sed como filósofo no se sacia viendo proyectadas en la pantalla del mundo las imágenes chinescas. Nancy mira al cristianismo y ve en su deconstrucción su objetivo, que pasa por ver qué hay detrás de esa pantalla de proyección, qué hay detrás de las oscuras sombras que no ven los espectadores, dónde está el proyector que ha mantenido durante tanto tiempo esta película en cartel:

La descristianización del Occidente no es una palabra vana, sin embargo mientras más intensamente sobreviene se hace más patente, a través de la suerte que han corrido las iglesias petrificadas y las teologías exangües, que aquello que nos ata aún, en muchos aspectos, al Occidente, son las nervaduras mismas del cristianismo. Nietszche había sostenido acertadamente que la sombra de Buda permanecería mil años ante la caverna en que Buda había muerto; nos encontramos en esta sombra, y es justamente esta sombra la que debemos sacar a la luz. Nos encontramos en las nervaduras del cristianismo; éstas nos mantienen, pero ¿`cómo? Este segundo axioma plantea así que la totalidad de nuestro pensamiento es de parte a parte cristiano ${ }^{41}$.

Nietszche hablaría a toro pasado en todo caso, casi a 2500 años de distancia, en los que se ha extendido el budismo como un canto a la retracción de un yo que es la fuente de todos nuestros sufrimientos, un canto al no-ser como meta a alcanzar para no caer en la incesante rueda de las reencarnaciones en este samsara que es el mundo en el que vivimos. Esta sombra sigue extendiéndose como también se extiende la sombra del cristianismo, por usar el símil de Nancy, de tal forma que somos cristianos, queramos o no, en la totalidad. Esta sombra en la que estamos, según Nancy, no es fácil de ver al primer golpe de vista si la extendemos sobre lo

${ }^{40}$ Ibidem, pp. 13-14.

${ }^{41}$ Nancy, J.-L., La desconstrucción del cristianismo, Ediciones Buenos Aires, La Cebra, 2006, pp. 33-35. 
primero que vemos con nuestros propios ojos. Es necesario distanciarse del objetivo de nuestra mirada para captar todos y cada uno de los detalles con mayor nitidez:

... no se trata de despojarse de una tradición, de desprenderse de una vieja piel, sino que precisamente se trata de enfrentar aquello que llega al Occidente y al cristianismo desde más lejos que éstos mismos, aquello que desde el fondo de nuestra tradición llega a nosotros como algo más arcaico (por supuesto, en el sentido de un arkhè, y no de un comienzo histórico) que el cristianismo mismo. Para decirlo de otro modo, la cuestión es saber si podemos, volviéndonos sobre nuestra procedencia cristiana designar desde el seno del cristianismo una procedencia del cristianismo más profunda que el cristianismo mismo ${ }^{42}$.

Nuestro autor declara la intención de volver sobre nuestros pasos ya pensados, instalarse en una atalaya desde la que no se puede ver ofendido el creyente ni el ateo, porque esta búsqueda va más allá de cualquier credo.

Nancy parece hablar aquí como un presocrático que mira a su alrededor con ojos de asombro, para captar la sonoridad del mundo desde una mirada prefilosófica, y no se da por satisfecho con una explicación que manifieste que todo está lleno de dioses en un territorio en el que la razón se rinde ante una irracionalidad que linda con lo sagrado:

No hay que olvidar, en efecto, que la frase del prefacio de la Crítica, «He tenido que suprimir el saber para dar lugar a la creencia», abre hacia una creencia en los límites de la razón. Se olvida a menudo que ese es el objetivo de Kant, y que de lo que se trata, en realidad, con la modernidad, es de otra cosa que de una desviación o de un abandono. La verdad es de otro orden -sin ser, sin embargo, de un orden inverso-, si es que lo inverso consiste en decir que la descomposición interna del cristianismo ha entregado a la sociedad occidental a su errancia moderna ${ }^{43}$.

Esta responsabilidad que Nancy carga sobre los hombros de un cristianismo que hoy acoge -no desde planteamientos teóricos sino desde de la acción social y real-a los hombres y mujeres que se han quedado desorientados en las calles es otro de los rasgos de la continua deconstrucción cristiana. Porque atiende a creyentes y a personas sin credencial de credo, hombres rendidos ante una crisis que ha saltado del ámbito económico para continuar errante por otras parcelas de la vida:

La identidad cristiana se constituye así, desde la partida, a través de la autosuperación: la Ley antigua por la Ley nueva, el logos por el Verbo, la civitas por la civitas Dei, etc., el esquema propio al cristianismo es diferente justamente porque corresponde a una ortodoxia que se concibe a sí misma como el movimiento, virtualmente infinito, a través del cual una fe se descubre al referirse a aquello que la precede, y a lo cual renueva y esclarece... Se trata de algo único: la fe cristiana es

42 Ibidem, p. 37.

43 Pp. 39-41. 
ella misma experiencia de su historia, experiencia del plan perseguido por Dios para la ejecución de su salvación ${ }^{44}$.

La ciudad de Dios de san Agustín, escrita entre el 410 y el 423 d.C., "ha sido frecuentemente considerada la afirmación más autorizada de la superioridad del poder eclesiástico sobre el secular», al considerar la presencia de Dios como justificación de los procesos históricos y explicación de un modelo de temporalidad lineal hacia la salvación, que rompe con la helénica visión circular del tiempo, creando así un nuevo clima en el que se debaten el homo politicus y el homo credens. El cristianismo supo interpretar las claves de su época inicial y sostuvo, como hoy los sostiene abiertos a la crítica, valores y aspiraciones que sintonizan con los intereses humanos, y de esta manera manifestarse como la voz universal que hoy se pone bajo sospecha. Esta supervivencia cristiana interesa al pensamiento de Nancy desde los más profundos cimientos, desde los primeros textos cristianos en que ya se establecía una moral de paso, para estar en esta vida, porque el cristianismo siempre ha tenido claro que su reino no es de este mundo sin sentido.

Todo se juega entonces en este punto: pensar la infinidad del sentido, pensar la verdad como infinito del sentido. $\mathrm{O}$ aún más, pensar el sentido como una apertura absoluta del sentido y al sentido, pero a un sentido de alguna manera vacío, vacío de todo contenido, de toda figura, de toda determinación. Digamos, sin jugar y jugando con las palabras, que esta es "la cruz del cristianismo", ya que es exactamente en este punto que éste último de constituye y, simultáneamente, se deshace. Es en consecuencia apuntando a este punto que convengo en tratar de desconstruir el cristianismo ${ }^{45}$.

A este sinsentido es a lo que se enfrenta también el cristianismo al dar cuenta de la irracionalidad de nuestras acciones si tiene como única meta nuestra corta estancia en el mundo. Quizá porque el viejo debate entre razón y fe no tiene consistencia hoy si se plantea como un debate entre verdades absolutas, herméticas, clausuradas a la ventilación, debería plantearse más bien como un debate entre verdades dialogantes, no excluyentes entre sí:

La tesis de Nancy, ya lo hemos adelantado, consiste en afirmar que el cristianismo es, por sí mismo y en sí mismo, deconstrucción. Mejor aún: una auto-deconstrucción. Es el cristianismo el que indica de forma más radical cómo el monoteísmo... aloja en su seno, de la manera más íntima, el corazón vacío del vacío mismo, esto es, más dentro de sí que su misma intimidad, el principio de un mundo sin Dios ${ }^{46}$.

Dice Nancy, por otro lado, que «hace tiempo que no somos cristianos» al creer el cristianismo como un «bloque autónomo», en la distancia, y se afana en

\footnotetext{
44 P. 47.

45 P. 55.

46 Rodríguez Marciel, C., Nancytropias, Madrid, Ed. Dykinson, 2011, p. 311.
} 
sacar a la luz lo no revelado por el cristianismo. Esa nada que duerme detrás, en un antes, del Antiguo y del Nuevo Testamento, si hablamos del cristianismo católico, como si hubiera una solapada intencionalidad que alienta una esperanza sin sentido, que no solo se despliega en la realidad mundana sino que se reafirma en la creencia de otro mundo eterno. Nancy trata de desmontar el cristianismo negando que exista tal conciencia cristiana en quienes son su propia base, la masa de creyentes, para preguntarse sin rodeos:

¿Qué es el cristianismo? Es el Evangelio. ¿Qué es el Evangelio? Es aquello que se anuncia, no los textos. ¿Qué es lo que se anuncia? Nada. Marcel Gauchet ha llamado la atención, como lo hiciera Nietzsche anteriormente, sobre el escaso espesor de los cuatro Evangelios: son casi nada ${ }^{47}$.

Aquí Nancy dispara sin dudarlo a la línea de flotación, al núcleo de la palabra como texto escrito y como verdad venerada, y da más garantía a lo que se anuncia y que no está dicho en la palabra, que se escucha, que a lo que se lee, al declarar los Evangelios como un frío desierto poblado de un silencio que nada dice. Aunque ni siquiera en lo anunciado encuentra nada que echarse a la boca. Desacredita toda hermenéutica que se detenga a mirar con lupa los textos evangélicos por juzgar que están lejos de la verdad, sin garantía para ser proclamados como manifiesto de la nueva alianza que se inaugura con la llegada de Cristo. El texto evangélico deja a Nancy como está, y nos invita más bien a escuchar lo que se «anuncia» en los Evangelios y que no aparece escrito, lo que se dice sin escuchar la sonora presencia de la palabra, esté escrita o no, porque será ahí, en lo ausente, donde se halla el principio de la deconstrucción que él anuncia.

\section{A MODO DE CONCLUSIÓN}

Nancy se esmera en escuchar desde el perímetro de las cosas, desde los contornos que amenazan con el abismo de lo no pensado, como ya comenté. Su pensamiento ilumina nuestro presente. Su filosofía puede darnos la impresión de ser una filosofía impregnada de un seductor carácter inactual, como síntoma claro del vigor que la recorre. La originalidad de sus trabajos, publicaciones, en algunos casos breves, pero no por ello carentes de un extraordinario interés. Nancy hace tambalear los cimientos de pensamientos asentados por la inercia de la tradición, se despoja de las vestiduras y va por libre de otras voces y libre de sí mismo. Se descarna de sellos que han dejado marcas y relieves en la cultura de Occidente para ser solo pensamiento que penetra en lo aprendido. Se posiciona fuera del ensimismamiento del pensar condicionado. Si jugamos con uno de sus títulos, $A$ la escucha, poner oído, estar a la escucha de los diversos temas nancyanos, sin pretender abarcarlos en toda su amplitud, 2006. p. 63.

${ }^{47}$ Nancy, J.-L., La desconstrucción del cristianismo, Buenos Aires, Ediciones La Cebra, 
como es lógico, es aventurarse en un lenguaje salpicado de neologismos que alcanzan el tema del cuerpo al ser uno de los blancos a los que apunta. El cuerpo, que no es un cadáver diseccionado en una fría clase de anatomía, ni es un cuerpo objetivo que leemos en tercera persona, es el cuerpo que no es posible diseccionar en vida, ni trocear con el bisturí de un lenguaje que no termina de atrapar todos los «indicios» que lo conforman. Y cuando habla de escucha Nancy desde los primeros compases lleva al lector al territorio exacto de la escucha referida. Se zafa de anteriores significados vinculados a la escucha como un lugar ubicado a la sombra, al acecho, en una escucha agazapada entre el follaje, como quien está a la espera, sigiloso, y desea hacerse con una escucha donde importa más lo sonoro que lo que puedan significar los sonidos codificados por la razón. Nos conduce a escuchar a pecho descubierto, sin filtrar códigos, la sonoridad de la voz humana o los matices más sutiles de un violín, de un piano, la vibración sin nombre de un violoncelo que se desborda para instalarse en lo que está por pensar, y así dudar hasta de la sonoridad de la propia escucha. Para Nancy tiene un gran valor el sentido del oído y hace parejas con «ver y mirar, oler y husmear u olfatear, gustar y paladear, tocar y tantear o palpar, oír y escuchar», como si estos emparejamientos dejaran entre sí un vacío libre de carga semántica, liberado de la codificación que todo lo sella. Nancy no solo busca instalarse en el desborde, sino que al emprender esta arriesgada incursión por los límites se encamina también a los orígenes, a un espacio virgen en el que ha crecido la maleza sin control, y donde los significantes y los significados no existen como tales por no rendir pleitesía a lo codificado. Es una continua vigilancia que invita a no bajar la guardia en el pensar. Y esta filosofía también la aplica Nancy no solo a la estética de lo sonoro -sea la voz humana, el ruido del viento o una melodía-, sino que también está presente como estrategia cuando extiende la mirada, o más bien el oído filosófico, a otros asuntos. Nancy se ocupa también con buen tino de problemas que están latentes, en peligroso periodo de incubación, como son los brotes neonazis de nuestro tiempo, que recuerdan el horror «del exterminio programado de judíos». Por eso advierte de que el presente no se ha liberado de los vínculos con el pasado, manifiesta su preocupación filosófica por las formas posibles de la repetición.

El mundo y el arte. Dos elementos que se relacionan en su totalidad. El arte, según Nancy, no tiene vínculo con la historia ni con eso que llamamos verdad, ni le atribuye una trascendencia metafísica que puede confundirse con lo religioso, el arte como portavoz de un mundo trascendente admitido como consuelo. El arte se relaciona directamente con el mundo, a él dirige sus mensajes y de él recoge la resonancia de la sonoridad enviada desde una composición musical, una instalación artística o una tela impregnada de emociones. Es en la unidad aparente e «impresentable» del mundo en la que Nancy detecta su fragmentación. Por otro lado, el pensamiento nancyano se ocupa de algo que experimentamos casa día: el sueño. Su lectura sobre el sueño no es una lectura desde el psicologismo desmedido, porque no escucha o lee el sueño instalado en la vigilia. La noche de los párpados es preludio del sueño, es la caída en la negrura del sueño, en el oscurecimiento de las formas y los colores. La noche, a la que Nancy atribuye una igualdad constante, sin dar cuenta de lo que reclama la vigilia que distingue los días, la vigilia que es la condición que antecede a la caída en el sueño. 
Tumba de sueño es una reflexión sobre el sueño, sobre los procesos no medibles de ciertos registros que se dan en el extraño mundo del durmiente, no palpables a través de una tecnología que avanza pero que no se hace con verdades sino con móviles espejismos. La simultaneidad temporal que Nancy atribuye al sueńo hace posible una especie de eterno presente, una "copresencia» donde lo compatible convive con lo incompatible, donde las rupturas oníricas no parecen alterar la lógica de quien duerme, de un yo que aparece estampado en un film poblado de pesadillas o de sueños posibles. Un yo que se ve a sí mismo mientras tiene los ojos cerrados. La identidad en el sueño carece de referencias que afiancen el yo, porque el yo se introduce donde no parece clara la distinción del durmiente y la escenografía de la que también forma parte, porque la mirada de la vigilia ha sido sustituida por unos ojos que miran hacia dentro.

El cuerpo ocupa un lugar primordial en el pensamiento de Nancy, sus reflexiones van más allá de una visión inmanente del mismo como aparece en la ontología spinozista; rompe con el discurso cartesiano de la res extensa y la res cogitans que sigue instalado en nuestra realidad. Nuestro autor cuando habla de cuerpo no habla como una parte exterior que sirve de estuche a otra materia no medible ni visible, que es el alma. Una unidad que se nos hace legible a través de "vestigios» que siempre nos darán una aproximación imprecisa y no definitiva, dispersa, sin una imagen global que pueda calmarnos la curiosidad.

Levanta la voz y reclama para el cuerpo una filosofía que no se agota. Según Nancy el cuerpo no conoce, solo siente; parece ironizar sobre lo ya sabido sobre nuestra corporeidad o con lo ya dicho por la neurociencia para ir al borde de lo que se sabe y plantar nuevos interrogantes, nuevos hitos que se desdibujan a lo lejos. No deja espacio a quienes atribuyen al hombre una trascendencia que se zafa de lo físico para instalarse en el territorio donde se fabrican los mitos, las esperanzas de una vida no material y, al mismo tiempo, hace palidecer el suelo que sostiene las creencias religiosas que miran con optimismo hacia el otro mundo. En La desconstrucción del cristianismo, Nancy deja claro que el cristianismo se empieza a «desconstruir» desde sus propios orígenes. Tal vez en este deshacerse a sí mismo en tiras se halle una de las claves más destacadas de la supervivencia del cristianismo. Nuestro autor declara la intención de volver sobre nuestros pasos ya pensados, instalarse en una atalaya desde la que no se puede ver ofendido el creyente ni el ateo, porque esta búsqueda va más allá de cualquier credo. Nancy está interesado en captar la sonoridad del mundo desde una mirada prefilosófica, y no se da por satisfecho con una explicación que manifieste que todo está lleno de dioses en un territorio en el que la razón se rinde ante una irracionalidad que, tal vez, linda con lo sagrado. 
